\title{
LA HOMOLOGACIÓN DE TÍTULOS EXTRANJEROS EN ESPAÑA, EVOLUCIÓN DEL SISTEMA Y RESTRICCIONES INJUSTIFICADAS
}

\author{
Fernando LOSTAO CRESPO \\ ABOGADO \\ ASESORÍA JURÍdica FundaCión UniVERSITARIA SAN PABLo CEU*
}

SUMARIO: I. La evolución del régimen de homologación de títulos universitarios extranjeros en España. I.I. Homologación clásica: sólo a títulos del catálogo. I.2. La introducción de la homologación a grados académicos (2004-20I4). I.3. Sistema vigente desde noviembre de 20 I4. II. La limitación del concepto de homologación a titulaciones profesionales y la nueva vía de la declaración de equivalencia. III. Homologación profesional y reconocimiento profesional en el ámbito Europeo. IV. Análisis crítico del nuevo sistema. IV.I. Requisitos confusos. IV.I.I. Primer requisito. Expedición oficial del título. IV.r.2. Segundo requisito. Requisitos de acceso. IV.I.3. Tercer requisito. Superación de un ciclo completo de estudios. IV.r.4. Cuarto requisito. Competencias formativas. IV.2. Exclusiones que se extralimitan. IV.2.I. Estudios realizados en centros españoles no autorizados. IV.2.2. Planes de estudios no efectivamente implantados. IV.2.3. Títulos que reconozcan más de $15 \%$ de créditos por ejercicio profesional. IV.3. Incompatibilidades restrictivas. IV.4. Régimen transitorio retroactivo y limitativo. IV.4.I. La no especificación de que la resolución previa haya sido positiva. IV.4.2. ¿Y si la resolución previa ha sido positiva? IV.5. La nueva exigencia del nivel de idioma. V. Normativa marco. V.r. Principio de igualdad europea. V.2. Convenios europeos sobre reconocimiento de cualificaciones. V.3. Principio pro movilidad universitaria, pro colaboración y pro construcción de un sistema universitario único. V.4. Los principios que han de regir la actuación normativa de la administración. V.4.I. Principio de la irretroactividad de las disposiciones sancionadoras no favorables o restrictivas de derechos individuales, y de la retroactividad de las favorables. V.4.2. Principios de buena regulación administrativa.

RESUMEN: El régimen de homologación de títulos universitarios extranjeros español ha experimentado en los últimos doce años importantes cambios, pasando de un modelo clásico en que era esencial el estudio de cargas y contenidos, a otros en el que junto a la homologación clásica, se han incorporado una homologación más genérica, o de nivel, ahora llamada declaración de equivalencia. La desaparición del catálogo de títulos, ha supuesto también que desde el año 20I4, el concepto de homologación se reserve para aquellas titulaciones que tienen competencias profesionales. Aunque la evolución del sistema, pueda parecer positiva, por permitir el reconocimiento de esta genérica condición de universitario, también merece crítica por los números requisitos, exclusiones e incompatibilidades de carácter restrictivo que se establecen.

Palabras Clave: Homologación, títulos, universitarios, extranjeros, restricciones

ABSTRACT: The Spanish standards for recognition and approval of foreign university qualifications has undergone significant changes in the last I2 years. It has gone from a classical model where the study of duration and contents was essential, to a model where besides the classical recognition, another more generic approval regarding the level of qualification, referred to as attestation of equivalence, has been incorporated. The disappearance of the catalogue of awards in Spain has meant that since 20I4 the concept of approval procedures applies only to qualifications that carry professional competences. Even thou the evolution of the system may seem positive, allowing the recognition of a generic condition of a person with university studies, it also deserves criticism due to the number of requirements, exclusions and incompatibilities of restrictive character that are established.

KEYWORDS: Recognition, awards, university, foreign, restrictions

\footnotetext{
* fernando.lostaocrespo@ceu.es
} 


\section{La evolución del régimen de homologación de títulos universitarios extranjeros en España.}

El sistema de homologación en España de los títulos universitarios extranjeros, o por mejor decir, los sistemas para dar efectividad a los títulos universitarios extranjeros en España, ha sufrido en los últimos I2 años una importante evolución que puede sintetizarse de la siguiente manera.

\section{I.I Homologación clásica: solo a títulos del catálogo.}

Real Decreto 86/1987, de 16 de enero, por el que se regulan las condiciones de homologación de títulos extranjeros de educación superior (Vigente hasta el o4 de Septiembre de 2004).

De acuerdo con este clásico sistema de homologación, que estuvo vigente en España hasta hace apenas I2 años, sólo existía un tipo de homologación, y solo se podía pedir esta con respecto a un título de los existentes en el cerrado catálogo español de títulos universitarios. Como se recordará perfectamente por su cercanía en el tiempo, en España hasta la aparición del Real Decreto 1393/2007, por el que se establece la ordenación de las enseñanzas universitarias oficiales, todos los títulos universitarios oficiales eran aprobados por el gobierno central al promulgar las directrices generales propias de cada titulación.

La respuesta a una solicitud de homologación podría ser triple:

- Positiva.

- Negativa.

- Positiva condicionada a la superación en alguna universidad española de una serie de materias, o una prueba de conjunto.

El sistema se revelaba como claramente insuficiente, dado que en muchas ocasiones la titulación extranjera que se pretendía homologar no tenía una correspondencia clara con una titulación española determinada, y el titulado extranjero se quedaba sin ni siquiera obtener un genérico reconocimiento a su condición de universitario, que tan útil le podría resultar en determinadas circunstancias como las siguientes:

- Acceso a un concurso oposición convocado en cualquiera de nuestras administraciones, donde se exigiera estar en posesión de una titulación universitaria no específica.

- Clasificación profesional a efectos laborales.

- Acceso a curso de postgrado universitario.

- Utilización por las empresas de modelo de contrato que fomentaban la contratación de titulados universitarios.

- Obtención del título de técnico superior en prevención de riesgos laborales.

- Acceso al examen de traductor jurado. 
- Ni siquiera para que contará en el concepto de «otros méritos» en las oposiciones, se daba juego a los títulos universitarios extranjeros no homologados.

La cuestión era especialmente grave en el ámbito de los titulados universitarios de países pertenecientes a la Unión Europea, ya que al menos tres de los principios configuradores del derecho europeo, se podrían considerar vulnerados por esta tan estricta legislación y práctica española:

- Libre circulación de trabajadores.

- Libertad de establecimiento.

- No discriminación por razón de la nacionalidad del título.

De facto, se estaban poniendo injustificadamente más trabas a los ciudadanos europeos de otras nacionalidades, que a los propios nacionales, ya si a estos sólo se les pedía estar en posesión de un título universitario en términos generales, con independencia de la especialidad de este, no se debería haber exigido a los nacionales de otros países la homologación de su título universitario extranjero, porque era lo mismo que exigirles estar en posesión de una titulación determinada.

Existe una comunicación de la Comisión Europea -muestra el parecer de la comisión aunque no tiene rango de norma jurídica- de II de diciembre de $2.002^{\mathrm{I}}$, denominada, La libre circulación de trabajadores: la plena realización de sus ventajas y sus posibilidades, que sin duda refuerza la idea de la necesidad de que en todo el ámbito de la Unión Europea fuera respetada la genérica condición de universitario, de aquellos que tuvieran una titulación expedida por una universidad de un país miembro. Entresacamos una frase de la comunicación indicada de la comisión: «Cuando sólo cuente el nivel de estudios para cuya acreditación se concede un título, las autoridades del estado miembro de acogida no tienen derecho a tomar en consideración el contenido de la formación. Las autoridades del estado miembro de acogida sólo pueden tener en cuenta el nivel de dicho título».

Esta comunicación hace un resumen de la jurisprudencia de del Tribunal de Justicia de la Unión Europea sobre la libre circulación de trabajadores, y además de lo ya comentado, resalta el que no se pueden establecerse discriminaciones en razón a la nacionalidad del trabajador europeo, en el acceso a un puesto de trabajo en la empresa privada, en el acceso a la función pública -salvo excepciones muy contadas-, y que asimismo debe haber un tratamiento igualitario en razón al reconocimiento de a la antigüedad, experiencia profesional, sistemas de seguridad social

En relación toda esta problemática, existe una sentencia de del Tribunal de Primera Instancia de la Unión Europea (sentencia de 9 de diciembre de I.999, Asunto T-299/97)2

\footnotetext{
' http://eur-lex.europa.eu/legal-content/ES/TXT/?uri=URISERV:cI0525

${ }^{2}$ http://curia.europa.eu/juris/showPdf.jsf;jsessionid=9ea7d2dc3od 5827293afe6e84f4bgefa8acoraeacd 33. e 34 KaxiLc3qMb4oRchoSaxuSbN5o?text=\&docid=44882\&pageIndex=o\&doclang=ES\&mode=lst\&dir=\&occ=first\&pa $\mathrm{rt}=\mathrm{I} \& \mathrm{cid}=\mathrm{I} 66938$
} 
muy relevante, en particular en sus apartados 2I y 32. La sentencia es fruto de un recurso interpuesto por un ingeniero técnico español, al que la comisión le impide presentarse a una oposiciones tipo A, siendo que tanto los títulos británicos en «Bachelor of Arts», «Bachelor of Science» y «Bachelor of Engineering», y el título alemán «Fachhochschildiplom», que tienen todo ellos una duración y nivel parecido al ingeniero técnico español, sí que lo podían hacer. La sentencia da la razón al recurrente por un aspecto formal, ya que en la convocatoria de los puestos, no se había especificado la necesidad de que la titulación universitaria fuera de ciclo largo, aunque no deja de plasmarse un cierto mayor nivel de los «Bachelor» Británicos frente a las ingenierías y arquitecturas técnicas españolas, puesto que aquellos dan acceso al doctorado, cosa que no sucede con las carreras técnicas o diplomaturas españolas, pero lo importante del caso es que a los efectos de las instituciones europeas, ninguna importancia debía darse a que el título fuera homologado o no.

\section{I.2. La introducción de la homologación a grados académicos (2004-20I4).}

Real Decreto 285/2004, de 20 de febrero, por el que se regulan las condiciones de homologación y convalidación de títulos y estudios extranjeros de educación superior (Vigente hasta el 23 de Noviembre de 2014).

En el año 2004 se dio un paso adelante en este reconocimiento de la condición genérica de universitario, ya que junto a la homologación a un título del catálogo, se crea un nuevo tipo de homologación, la homologación a grado académico: niveles de diplomado, licenciando, Master y Doctor (los de postgrado correspondían a las universidades).

Esta nuevo tipo de homologación establecía en su artículo 19, los siguientes requisitos para esta nueva homologación de grado o de nivel:

1. Las resoluciones sobre la homologación a grado académico se adoptarán teniendo en cuenta los siguientes criterios:

a) La correspondencia entre los niveles de acceso académicos requeridos para el acceso a los estudios conducentes a la obtención del título extranjero y para el acceso al grado académico español de que se trate.

b) La duración y carga horaria del periodo de formación necesario para la obtención del título extranjero cuya homologación se pretende.

c) La correspondencia entre el grado académico de los estudios conducentes a la obtención del título extranjero y el correspondiente grado académico español al que se solicita la homologación.

2. Para la homologación al grado académico español correspondiente a los estudios oficiales de Grado, el título extranjero debe permitir en el país de procedencia el acceso a estudios oficiales de posgrado. 
Se creó además una especialidad para los casos en los que de homologación $y$ reconocimiento de títulos oficiales de educación superior expedidos en un estado miembro de la Unión Europea, en los cuales según el art. 2I de la misma norma sólo podrían exigirse los requisitos I c) y 2 del artículo I9.

Sin embargo, la postura proteccionista tanto del Ministerio de Educación Española, como del Consejo de Coordinación Universitaria español que emitía los informes, hizo que la práctica administrativa española evitara la equiparación de los títulos de «Bachelor» británico de tres años, con el nuevo título universitario español de grado, y ello básicamente por dos vías:

- Primero retrasando nada menos que 7 años el comienzo de la homologación a nivel de Grado.

- Segundo ofreciendo a los solicitantes de esta homologación de primer nivel universitario, la homologación a Diplomado, en lugar de licenciado.

En primer lugar, el Ministerio de Educación español, ha estado retrasando muchos años la posibilidad de solicitar la homologación de nivel -la hoy llamada declaración de equivalencia-, a nivel de Grado, y forzando la homologación a nivel de Diplomado de todo aquellos que hubieran estudiado tres años.

Y no decimos de modo injusto denunciando una falta de regulación necesaria, sino denunciando una falta de aplicación de una normativa vigente, dado que el título de Grado se introdujo en España en 2007, con el muy conocido Real Decreto 1393/2007, y el Ministerio no la ha hecho posible hasta la última reforma normativa de 20I4, por el simple mecanismo de no habilitar el formulario específico para ello.

En efecto, la aplicación del art. I8 del RD 285/2004, que es el que establecía la homologación al nivel de Grado, se excepcionaba por la DT $2^{\circ}$ I de la misma norma, que establecía de modo provisional la homologación a los niveles de Diplomado y Licenciado, y ello hasta la fecha prevista en la DF $4^{\circ} 2^{\circ}$ también del RD 285/2004, siendo dicha fecha la del momento en que se hubiera completado el proceso de renovación del catálogo de títulos universitarios oficiales, de acuerdo con lo señalado en el apartado $3^{\circ}$ de la disposición adicional primera del Real Decreto 55/2005, de 2I de enero, por el que se establece la estructura de las enseñanzas universitarias y se regulan los estudios universitarios oficiales de grado.

Pero lo cierto es que esta condición devino en de imposible cumplimiento, dado que, como es bien sabido, el RD I392/2007 no sólo derogó el RD 55/2005, sino que además derogó ( disolvió, eliminó...) el supuesto de hecho de la condición temporal, ya que nunca se iba a poder producirse dicha renovación del catálogo, puesto -como todos conocemosse transformó completamente el sistema universitario español, para pasar de un sistema de Catálogo, al sistema de Registro de títulos universitarios, en el Registro de Universidades Centros y Títulos, RUCT.

Por lo que, al ser imposible de todo punto que se produjera la renovación del catálogo de la que habla la DF $4^{a} 2^{\circ}$ del RD 285/2004, habría que haber considerado 
directamente aplicable el art. I8 del mismo RD 285/2004, y por ello el MEC tendría que haber habilitado los modelos para solicitar la homologación a nivel de Grado hace ya mucho tiempo. Cosa completamente coherente con el hecho de que desde el curso 2008/2009 se imparten en España estudios de grado.

En segundo lugar, porque a las personas poseedoras de un título de «Bachelor» Británico de 3 cursos de duración o I80 ETCS, que solicitaban la homologación al nivel de licenciado, al no existir, mejor dicho, al no querer el Ministerio implantar la de Grado, se les ofrecía rápidamente la de nivel de diplomado, al modo parecido al que hoy se ofrece un $50 \%$ en la rebaja de una multa por pronto pago. Y algún valiente, que se atrevió a desafiar esta postura ministerial que contrariaba en todo los criterios del citado art. 2I del RD 285/2004, se encontró con el portazo de la Audiencia Nacional y luego del Tribunal Supremo, apoyados todos en su decisión en un informe del Consejo de Universidades que hacía un estudio de cargas académicas, cuando es algo que según regula este precepto expresamente, no debía hacerse, al tratarse de un título universitario procedente de la Unión Europea.

Recordemos que según el art. 2i citado los dos únicos criterios que se deberían de tener en cuenta para la homologación de nivel eran:

- La correspondencia entre el grado académico de los estudios conducentes a la obtención del título extranjero y el correspondiente grado académico español al que se solicita la homologación. (Art. 19.1 c)

- Para la homologación al grado académico español correspondiente a los estudios oficiales de Grado, el título extranjero debe permitir en el país de procedencia el acceso a estudios oficiales de posgrado. (Art. 19.2)

Excluyéndose de modo expreso los otros dos requisitos que se si se exigían a los títulos universitarios no procedentes de universidades con sede en la UE:

a) La correspondencia entre los niveles de acceso académicos requeridos para el acceso a los estudios conducentes a la obtención del título extranjero y para el acceso al grado académico español de que se trate.

b) La duración y carga horaria del periodo de formación necesario para la obtención del título extranjero cuya homologación se pretende.

Pues bien, fue un informe del Consejo de Universidades sobre cargas lectivas el que justificó la negativa del Ministerio de Educación a homologar los títulos de «Bachelor» Británicos con los de licenciado español, siendo que los dos estaban en el mismo nivel en sus respectivos sistemas universitarios, y los dos daba acceso a postgrado en las Universidades de su territorio ${ }^{3}$. En realidad se impidió este acceso al nivel de licenciado a

\footnotetext{
${ }^{3}$ Además paradójicamente los artículos I6 y i9 del RD I393/2007, permitían el acceso directo a Masters y Doctorados de universitarios extranjeros, aunque no hubieran homologado el título. Hoy el acceso a doctorado sin necesidad de homologar los títulos se regula en el artículo 6 del Real Decreto 99/20II, de 28 de enero, por el que se regulan las enseñanzas oficiales de doctorado.
} 
los «Bachelor» de 3 años, porque a los de 4 años, y 240 ETCS, sí que se les equiparó. Todo ello porque -insistimos-, se hizo una comparativa de cargas académicas, no procedente.

Como se ha anticipado, la Audiencia Nacional confirmó este criterio ministerial, claramente erróneo a nuestro parecer, y lo mismo hizo el Tribunal Supremo en la sentencia de la sección $4^{\circ}$ de la sala de lo Contencioso Administrativo, de I2 de diciembre de 20II, en el recurso 3135/20IO. Sentencia que salvo error u omisión ha sido la única, y por lo tanto no ha hecho jurisprudencia.

Probablemente esta problemática se hubiera evitado si el Ministerio de Educación hubiera empezado a homologar a nivel de grado cuando correspondía, es decir 7 años antes.

Paradojas de las vida, el Real Decreto 43/2015, de 2 de febrero, ha modificado entre otros el art. I2 del Real Decreto 1393/2007, de 29 de octubre, por el que se establece la ordenación de las enseñanzas universitarias oficiales, permitiendo la posibilidad en España de títulos de grado de sólo tres cursos de duración, y i80 ECTS.

\section{I.3. Sistema vigente desde noviembre de $20 \mathrm{I} 4$.}

Real Decreto 967/2014, de 21 de noviembre, por el que se establecen los requisitos y el procedimiento para la homologación $y$ declaración de equivalencia a titulación $y$ a nivel académico universitario oficial y para la convalidación de estudios extranjeros de educación superior, y el procedimiento para determinar la correspondencia a los niveles del marco español de cualificaciones para la educación superior de los títulos oficiales de Arquitecto, Ingeniero, Licenciado, Arquitecto Técnico, Ingeniero Técnico y Diplomado.

El concepto de homologación que en la normativa de homologaciones previa -el RD 285/2004, de 20 de febrero-, se había extendido sobre su configuración tradicional, ya que aquel habría creado junto a la homologación a un título del catálogo, la homologación que ha sido llamada homologación de nivel o de grado ${ }^{4}$, vuelve a encogerse, y de alguna manera privilegiarse, ya que el concepto de homologación se reserva ahora sólo para pocas titulaciones, en concreto sólo para aquellas que en España dan acceso a una profesión regulada, y que son las que contienen en el anexo I del nuevo reglamento.

En realidad la desaparición del catálogo de titulaciones por obra del conocido RD I393/2007, de 29 de octubre, hacía pensar en la perdida de sentido de la homologación de títulos extranjeros, al menos como hasta como hoy la conocíamos, y su sustitución en la práctica por procesos de reconocimiento de créditos individuales en cada una de las Universidades del sistema español. Aunque también es cierto, que se hacía difícil pensar en que una universidad fuera reconocer de «una sola tacada» el ıo०\% de los créditos de una titulación extranjera, por más completa que esta fuera. El caso es que no se ha querido dejar en el olvido esta tradicional figura, y se le ha dado este nuevo sesgo, si bien es cierto que, antes las referencias se encontraban en el catálogo de títulos, y ahora se van a encontrar de un modo mucho más difuso, por un lado, en lo que se refiere sólo aspectos profesionales,

\footnotetext{
${ }^{4}$ En realidad en el art. I8 del RD 285/2004, se conocía con el confuso nombre «Homologación a Grado Académico correspondiente a los estudios universitarios oficiales de Grado».
} 
en la normativa específica que regula cada una de las profesiones referenciadas en el anexo I, y por otro en el propio RUCT.

De alguna manera, hubiera sido mucho más coherente con el actual sistema de registro abierto de títulos universitarios, el que la institución de la homologación hubiera pasado directamente a ser competencia de las universidades, sobre todo existiendo todavía, como veremos a continuación, la vía del reconocimiento profesional. Pero una vez más el estado no parece confiar mucho en los sujetos y en las organizaciones, y prefiere seguir amarrando competencias.

\section{La limitación del concepto de homologación a titulaciones profesionales, y la nueva vía de la declaración de equivalencia.}

La llamada homologación del nivel o grado que trajo consigo el anterior RD de homologaciones en su artículo i8, y que respondía a la necesidad de otorgar un justo nivel universitario a aquellos titulados extranjeros, cuya titulación no encajaba con las del catálogo existente en ese momento en España, ni correspondía tampoco a ninguna profesión «universitaria» de las contempladas en la distintas Directivas de las UE, ha sido sustituida por esta nueva figura de la Declaración de Equivalencia.

Las referencias de esta nueva declaración de equivalencia de título son las que se establecen en el Anexo II del nuevo Real Decreto, dentro de dos niveles distintos: Rama de Conocimiento (las creadas por el anexo II del RD i393/2007), y dentro de estas ramas, el Campo Específico (referidos al documento denominado CINE - campos de Educación y Capacitación Permanente).

El problema es que la corta lista de este anexo II, puede originar insatisfacciones:

En unos casos por establecer campos demasiados genéricos como por ejemplo el de las Humanidades.

- En otros casos por su ambigüedad, por ejemplo el caso de las ciencias sociales y del comportamiento, o el de competencias personales y desarrollo.

- Y en otros porque se queda corto: piénsese por ejemplo en todo el amplio campos de las ciencias económicas, financieras y contables, la administración y dirección de empresas, la publicidad, el marketing, que no parecen encontrar un acomodo -a no ser que sea en el muy genérico de las ciencias sociales, o muy forzado en el de educación comercial o de administración-, en los campos específicos de las rama de las Ciencias Sociales y Jurídicas.

La declaración de equivalencia podrá hacerse tanto a los niveles académicos de Grado o Master; art. I a $2^{\circ}$ del RD 937/20I4. Sin embargo, la declaración de equivalencia al nivel académico de Doctor que ya era competencia de las Universidades, sigue siendo competencia de las mismas; DA 5 del nuevo RD 967/2014. 


\section{Homologación profesional y Reconocimiento profesional en el ámbito europeo.}

La nueva restringida y privilegiada homologación «profesional», inevitablemente se va a confundir con la institución del Reconocimiento Profesional que se regula en el Real Decreto 1837/2008, de 8 de noviembre, por el que se incorporan al ordenamiento jurídico español la Directiva 2005/36/CE, del Parlamento Europeo y del Consejo, de 7 de septiembre de 2005, y la Directiva 2006/100/CE, del Consejo, de 20 de noviembre de 2006, relativas al reconocimiento de cualificaciones profesionales, así como a determinados aspectos del ejercicio de la profesión de abogado.

Y aunque es cierto que se trata de instituciones reguladas por normativas distintas, y con alcance distinto (la homologación más completo y el reconocimiento profesional más limitado), también lo es que en España ya estaba consolidada la vía del reconocimiento para la actividad profesional, y el introducir ahora una homologación con efectos profesionales y académicos a la vez, se puede generar confusión.

En la práctica nos vamos a encontrar con tres listas de profesiones:

- Las que conducen a un reconocimiento profesional automático. Las profesiones que tienen la formación armonizada (médico, médico especialista, enfermera responsable de cuidados generales, odontólogo, de veterinario, farmacéutico y arquitecto) y posibilitan el reconocimiento profesional automático establecido en el art. 30 del RD I837/2008.

- Las de la nueva homologación profesional. Las que configuran la lista de la nueva homologación profesional recogida en el anexo I del nuevo RD 967/20I4, tales como las profesiones sanitarias, las ingenierías y arquitectura, la abogacía y procuraduría, o las profesiones docentes preuniversitarias.

- Las que no conducen a un reconocimiento profesional automático. Las profesiones que no tienen formación armonizada, y que deben cumplir las condiciones previstas en el art. 2I en relación con el art. I9 y el anexo VIII del RD I837/2008.

\section{Análisis crítico del nuevo sistema}

IV.r. Requisitos confusos.

En la anterior normativa de homologaciones, el RD 285/2004 nos encontrábamos con un artículo que regulaba las causas de exclusión (art. 5), y otro que contenía los criterios para la homologación (art.9). En el nuevo RD 967/20I4 juntos a las causas de exclusión (art. 3), y los criterios de homologación (art. 8), cuyos enunciados se mantienen, se han introducido en el art. 7 lo que se denomina los requisitos de los títulos universitarios extranjeros. Vamos a realizar un breve análisis para ver que aporta de novedoso este artículo, y que crítica se le puede hacer. Requisitos de los títulos universitarios extranjeros: 
IV.I.I Primer requisito. Expedición oficial del título.

a) Haber sido expedidos por una autoridad competente del país de origen designada con arreglo a las disposiciones legales, reglamentarias o administrativas de dicho Estado.

Este es el único que verdaderamente tiene que ver con el título en sí mismo, pero en realidad se parece mucho a la causa de exclusión prevista en el Art. 2 p3 de la misma norma: Los que carezcan de validez académica oficial en el país de origen.

IV.I.2. Segundo requisito. Requisitos de acceso.

b) Acreditar que su poseedor cumple los requisitos de nivel de estudios exigidos en España para el acceso a la formación de Grado o Máster.

Este requisito del título, que más bien parece del titulado, se parece también mucho al criterio de homologación establecido en el art. Io pi a) del mismo RD 967/2014: La equiparación entre los niveles académicos requeridos para el acceso a los estudios conducentes a la obtención del título extranjero y para el acceso al título o titulación española

La introducción de este requisito del título, por esta vía, que también está incluido como criterio de homologación, parece pretender sortear lo dispuesto en el art. Io 4 del nuevo RD de Homologaciones, que se refiere específicamente a la homologación de títulos europeos:

Criterios específicos para la equivalencia a nivel académico de Grado y Máster. Cuando se solicite la equivalencia a nivel académico de un título correspondiente a enseñanzas realizadas conforme a sistemas educativos de países de la Unión Europea, EEE y Suiza, la resolución de declaración de equivalencia a titulación y a nivel académico tendrá en cuenta únicamente los criterios establecidos en el apartado 1.c), según los criterios y estándares utilizados por la Comisión Europea

Es decir, los criterios para la declaración de equivalencia de los niveles académicos de los títulos universitarios de la UE, EEE y Suiza son más flexibles que el resto, y por ello, pudiera parecer que lo que se pretende por esta nueva vía de los requisitos del títulos, es darle la vuelta al asunto, y poder así exigir a los titulados europeos los requisitos de acceso, que según el propio art. Io 4, y también la normativa anterior (art. 2I del RD 285/2004), no deben exigirse.

IV.r.3. Tercer requisito. Superación de un ciclo completo de estudios.

c) Acreditar que su poseedor ha superado un ciclo completo de estudios postsecundarios que acredite un nivel académico equivalente a la de los títulos de Grado o Máster.

Este requisito del título, que también parece más del titulado, se parece de igual modo mucho al siguiente criterio de homologación establecido en el art. Io pi c) del mismo RD 967/20I4: La equiparación entre los niveles académicos del título extranjero y del título o titulación española a la que se solicita la homologación o la equivalencia a titulación y a nivel académico 
Y en cualquier caso sería algo contenido en la propia esencia del título universitario. Para eso se expide un título universitario precisamente, para acreditar que se ha superado un ciclo de estudios postsecundarios; ¿qué sentido tiene exigir esto como un requisito adicional, cuando afecta a la esencia de los que es el título en sí mismo?

\section{IV.I.4. Cuarto requisito. Competencias formativas.}

d) Acreditar que se han obtenido las competencias formativas propias del título al que se solicita la homologación.

Este requisito, que también parece más un requisito del titulado que del título, sí que supone una novedad completa, que sirve una vez más, para introducir un elemento de confusión en el sistema, ya que no sólo se trata de un requisito de muy difícil valoración, sino que además me atrevería a decir, que carece de sentido en sí mismo, que es un elemento ex pureo que se introduce como arma proteccionista o arancelaria de la que se dota el MECD, para poder echar atrás la homologación de ciertos títulos extranjeros.

La evaluación de las competencias formativas, aparte de tratarse de un elemento novedoso en nuestro sistema educativo universitario, me atrevería a decir que poco calibrado y asentado todavía, es un elemento en el que en todo caso habrán tenido que entrar los docentes de la universidad expedidora del título en el proceso de evaluación; ¿qué se pretende?, ¿qué el comité técnico de la ANECA se meta a reexaminar a todos los titulados extranjeros que solicitan la homologación? Parece que indudablemente se está yendo demasiado lejos, invadiendo la esfera de otros, e introduciendo elementos de confusión en el sistema.

IV.2. Exclusiones que se extralimitan.

Nos fijaremos para su comentario en las reguladas en los apartados b y d del párrafo 2 del artículo 3 del RD 967/2014.

Art.- 3 Exclusiones

2. No serán objeto de homologación, equivalencia a titulación y a nivel académico universitario oficial o convalidación, los siguientes títulos o estudios expedidos o realizados en el extranjero:

b) Los correspondientes a estudios realizados, en todo o en parte, en España, cuando los centros carezcan de la preceptiva autorización para impartir tales enseñanzas, o bien cuando las enseñanzas sancionadas por el título extranjero no estuvieran efectivamente implantadas en la Universidad o institución de educación superior extranjera en el momento en que ésta expidió el título, de acuerdo con lo señalado en el artículo 86 de la Ley Orgánica 6/2001, de 21 de diciembre, de Universidades. No obstante, cuando esas circunstancias afecten sólo a parte de los estudios realizados, los estudios parciales que no incurran en ellas podrán ser objeto de convalidación, en su caso. 
IV.2.I Estudios realizados en centros españoles no autorizados.

Los correspondientes a estudios realizados, en todo o en parte, en España, cuando los centros carezcan de la preceptiva autorización para impartir tales enseñanzas.

Según esta disposición, no pueden ser objeto de homologación, declaración de equivalencia o convalidación, aquellos títulos cursados en centros radicados en España, cuando los mismos carecían de la oportuna autorización. Se hace referencia al conocido caso de los centros españoles que llegan acuerdos con universidades extranjeras, y la norma, tal y como está redactada, impediría que un alumno que ha obtenido una titulación tras realizar estudios en uno de estos centros no autorizados, pudiera obtener la homologación de su título, hubiera estudiado cuando hubiera sido, es decir, sin importar si el momento de realizar los estudios fue antes o no de la entrada en vigor de la Ley I/2006, Orgánica de Universidades, de 2I de diciembre. Es decir, sin recoger la consolidada jurisprudencia de la sala de lo Contencioso Administrativo del Tribunal Supremo sobre este particular. El estado de la cuestión es el siguiente:

Durante años el hoy Ministerio de Educación, Cultura y Deportes, en sus diferentes denominaciones, vino denegando la tramitación de las homologaciones de los títulos extranjeros, de todo aquel alumno que obtenía un título de una universidad de fuera de España, después de haber estudiado en un centro español que tuviera un convenio con la misma, y ello salvo que el centro extranjero estuviera autorizado. Es decir no daba ni siquiera pie a que por el comité técnico correspondiente se realizara el estudio de cargas y contenidos.

La denegación de la tramitación también se daba, aunque el tiempo estudiado sin autorización del centro hubiera sido parcial, y aquello resultaba injusto por al menos las siguientes razones:

I. Algunos de estos centros empezaron su actividad antes de que surgiera la norma reguladora correspondiente; es decir, antes de que entrara en vigor la Orden del Ministerio de Educación de 26 de mayo de 1993, que establece los requisitos para la autorización de centros universitarios extranjeros, que a su vez desarrollaba el Real Decreto 557/i99I, regulador de los requisitos para creación y reconocimiento de Universidades y los Centros Universitarios.

2. Esta normativa nada establecía sobre la relación entre la autorización del centro, y la homologación del título. Es decir, no se establecía que la autorización del centro español que tenía un convenio con una universidad extranjera, fuera un requisito necesario para que los alumnos pudieran homologar el título obtenido tras cursar estudios en uno de estos centros. Títulos que en cualquier caso siempre eran expedidos por la Universidad extranjera correspondiente, y no por los centros españoles con los que se ceebraba el convenio.

3. Tampoco el Real Decreto que regulaba entonces la homologación de títulos extranjeros, el Real Decreto 87/1986, diferenciaba entre homologación de títulos extranjeros después de haber estudiado en el extranjero, o después de haber estudiado en 
España en un centro que tuviera un convenio con una universidad extranjera. Es decir ni siquiera se contemplaba esta opción. Era un caso de evidente vacío legal.

En definitiva las resoluciones del MECD, no tenían amparo legal, y además eras restrictivas de derechos de los administrados, por lo que resultaban nulas, por aplicación, entre otras normas de desarrollo, del art. 9.3 de la Constitución, que como sabemos, establece el principio de legalidad y prohíbe la arbitrariedad por parte de los poderes públicos, y la retroactividad de las normas restrictivas de derechos.

Todos estos argumentos fueron empleados sin éxito inicial frente al MECD, y posteriormente frente a la Audiencia Nacional. Si bien es cierto, que la Audiencia Nacional inicialmente acogía las pretensiones de los demandantes en los juicios contenciosos administrativos, y mandaba retrotraer las actuaciones para que el MECD hiciera el juicio de equivalencia pertinente, pero utilizaba una doctrina distinta a la que luego utilizó el Tribunal Supremo. Básicamente decía que lo que se llevaba a homologación era el título, y eso era independiente de donde se hubiera estudiado.

No fue hasta la Ley Orgánica de Universidades de diciembre de 2.00I (Ley 6/OI, de 2I de diciembre), hasta cuando expresamente se reguló esta cuestión estableciendo en el art. 86.3, que no se podrán homologar títulos extranjeros si se ha estudiado en centros españoles no previamente autorizados. Es decir, sólo a partir de la entrada en vigor de esa norma se podía oponer al procedimiento de homologación dicho obstáculo. De hecho la prueba de que hasta ese momento la administración actuaba sin cobertura legal, fue precisamente la aparición «ex novo» de esta disposición con rango de ley. Este último argumento ha sido recogido expresamente por el Tribunal Supremo en la jurisprudencia que citamos a continuación.

En abril de 2.005, la sala de los contencioso administrativo del Tribunal Supremo dictó una sentencia (sentencia $n^{\circ}$ de I2-abril-2005, recurso 6026/2002), en la que por primera vez acogió la tesis indicada, marcándose una línea jurisprudencial nueva. Aunque fue en un caso de reconocimiento profesional y no de homologación, lo importante fue el pronunciamiento relativo a los efectos de la autorización o no del centro español, en el que se impartía la enseñanza conducente a la obtención del título universitario extranjero, en ese caso de la Universidad de Gales.

La sentencia confirmo el criterio de la parte demandante para indicar que antes de la Ley Orgánica de Universidades de diciembre de 2.00I, había un vacío legal, y que por lo tanto las decisiones del MECD eran irregulares, por un razonamiento tan simple, pero tan básico, como que no se pueden dictar resoluciones contrarias a los intereses de los administrados, sin tener cobertura legal para ello. Esa doctrina fue confirmada en sentencias posteriores de la sala de lo Contencioso Administrativo del Tribunal Supremo, de los años 2006 y 2007 , entre otras:

- I9 de junio de 2006 (recurso 2296/2000)

- I6 de mayo de 2007 (recurso 7093/2004)

- 30 de noviembre de 2007 (recurso 3758/2005) 
Pero cuando todo parecía estar claro sobre este particular, la promulgación en febrero de 2004 de un nuevo Real Decreto de homologaciones, volvió a generar una época de incertidumbre, ya que tanto el MECD, como la propia Audiencia Nacional, adoptaron un criterio sorprendente en la aplicación de esta nueva normativa de homologaciones establecida por el Real Decreto 285/2004, de 20 de febrero, que regulaba de nuevo las cuestión de la homologación de títulos universitarios extranjeros, aunque ahora ya en el marco de la Ley Orgánica de Universidades del año 200I.

El artículo 5.2 de este RD, en coherencia con el art. 86.3 de la LOU, antes mencionado, establecía el que no se pueden homologar títulos extranjeros si se ha estudiado en centros españoles no previamente autorizados. Hasta aquí nada que decir, el problema surgió cuando a la hora de aplicar esta disposición, tanto el Ministerio de Educación, como luego sorprendentemente la Audiencia Nacional, adoptaron el criterio de considerar -en lo relativo a los impedimentos relacionados con la no autorización del centro-, el momento de la realización de la solicitud, y no de el de la realización de los estudios. Es decir si un titulado había estudiado en un momento anterior a la LOU -es decir cuando legalmente no se contemplaba la relación entre la homologación o reconocimiento profesional del título, y la autorización o no del centro-, pero solicitaba la homologación después de la entrada en vigor del RD 285/2004, se le aplicaba el impedimento de la no autorización del centro, en una suerte de aplicación retroactiva de una norma restrictiva de derechos, que volvía a chocar con los cimientos de nuestro sistema jurídico.

Afortunadamente la sala de los contencioso administrativo del Tribunal Supremo, volvió a reafirmar su criterio en el año 2009, considerando ilegal esa aplicación retroactiva de la norma, y dejando sentado con toda claridad que la normativa a considerar de cara a la homologación del título, en lo referente a este aspecto concreto impeditivo, es la del momento de realización de los estudios, y no de la solicitud de la homologación. Esta jurisprudencia se ha recogido entre otras en las siguientes sentencias:

- I6-6-2009, rec. I725/2008.

- 2I-7-2009, rec. I7I9/2008

- I5-I2-2009, rec. 4470/2008.

Esta jurisprudencia hizo rectificar a la sala de lo contencioso administrativo de la Audiencia Nacional, a partir de una sentencia del to de septiembre del año 2009, que en este aspecto cambio su jurisprudencia, y la adaptó a la del Tribunal Supremo. Más recientemente, a finales del año 20II, una sentencia de la sala $3^{\text {a }}$ (de los Contencioso Administrativo) del Tribunal Supremo de 7 diciembre del diciembre del año 20II, recurso 338/2010, que confirmaba otra de la sala correspondiente de la Audiencia Nacional, ha venido a confirmar esta doctrina. ${ }^{5}$

\footnotetext{
${ }^{5}$ «TERCERO.- El Tribunal Supremo ha cambiado este criterio y en recientes y numerosas sentencias de la Sala Tercera, Sección 4, de I6 de junio de 2009 (recurso I92I/2008) EDJ 2009/134787 de 2I de julio de 2009 (recurso I7I9/2008) EDJ 2009/I7I73I de 2I de julio de 2009 (recurso: 7I57/2005) EDJ 2009/I7I754 de 23 de julio de 2009 (recurso: 828/2008) EDJ 2009/171753 entre otras muchas, se casan las sentencias dictadas por
} 
Pues bien, la aplicación de la actual redacción del primer inciso del art. 3.2.b), del nuevo Real Decreto 967/2014, puede llevar a que se vuelva a dar la situación que se dio con la entrada en vigor del hoy sustituido RD 285/2004, es decir que se impida la homologación, declaración de equivalencia o convalidación, a una persona que solicite una cualquiera de ellas, pero hubiera estudiado en un centro no autorizado antes de la entrada en vigor de la LOU en diciembre del año 200I, y que sea necesario volver a los tribunales a aclarar este punto.

IV.2.2 Planes de estudios no efectivamente implantados.

El segundo inciso del artículo 3.2b) del RD 967/20I4, dice: o bien cuando las enseñanzas sancionadas por el título extranjero no estuvieran efectivamente implantadas en la Universidad o institución de educación superior extranjera en el momento en que ésta expidió el título.

Esta disposición parece desconocer que los sistemas de organización de las universidades son muy variados, y por ello también, los de generación de títulos universitarios, y que una misma universidad puede tener títulos distintos en sus centros propios, y en sus centros asociados o adscritos, y que puede haber universidades organizadas de forma federal, que no tengan como tal ningún centro propio, o que incluso bajo una misma denominación de título universitario, se puedan dar planes de estudios sensiblemente distintos.

Ejemplo de universidad federal en España es la Universidad Ramon Llul, cuyas normas de organización y funcionamiento actualmente vigentes, aprobadas por el acuerdo del Gobierno de Cataluña 99/22/20I0, (BOE 3 de marzo de 20I4), describen este modelo de organización en su artículo I.4. ${ }^{6}$ Ejemplo de titulaciones universitarias que se imparten sólo en centros adscritos, y no en centros propios es el Grado de Turismo de la Universidad de Zaragoza," que se imparte sólo en la escuela universitaria de turismo de Zaragoza que es un centro privado adscrito a dicha universidad ${ }^{8}$. Y exactamente lo mismo, y con el mismo

este Tribunal en asuntos similares al que nos ocupa, y se acoge la tesis consistente en que lo trascendente a los efectos de homologación es la normativa existente en el momento en el que se cursaron los estudios y no en el momento en el que se solicita la homologación pretendida por lo que habrá que estar a la normativa entonces vigente para determinar si era necesario o no que el centro radicado en España contase con la preceptiva autorización administrativa. Por lo que si los estudios se cursaron antes de que entrase en vigor la Ley Orgánica 6/200I y el RD 285/2004, resultaba aplicable para la homologación la anterior normativa, constituida por la Ley Orgánica II/I983 y del Real Decreto 86/1987, normas en las que no era exigible para obtener la homologación, el requisito de que los centros radicados en España en los que se hubiera seguido toda o parte de la formación necesaria para obtener el título universitario extranjero contaran con la autorización prevista en el Real Decreto 557/I99».

${ }^{6}$ «4. La Universidad Ramon Llull está integrada por instituciones federadas, a partir de las cuales se crean los centros universitarios -escuelas y facultades, departamentos, institutos universitarios de investigación y otros centros o estructuras-. Las instituciones federadas que integran la Universidad son: el Instituto Químico de Sarrià CETS Fundación Privada, la Fundación Blanquerna, la Fundación Universidad y Tecnología La SalleFUNITEC, la Facultad de Filosofía, la Fundación ESADE, la Fundación Pere Tarrés, la Fundación Observatorio del Ebro, la Fundación Cardenal Vidal i Barraquer, el Instituto Borja de Bioética y la Fundación Xavier.»

\footnotetext{
${ }^{7} \mathrm{http}: / /$ titulaciones.unizar.es/turismo/

${ }^{8}$ http://etuz.es/
} 
título pasa en la Universidad de La Coruña, cuyo título de Grado en Turismo sólo se imparte en un centro adscrito. ${ }^{9}$

Con ello ya podemos empezar a llegar a la conclusión de que exigir para poder homologar un título universitario extranjero después de haber estudiado en un centro español, que sea necesario que el título esté efectivamente implantado en la universidad que expide el título, es una exigencia no coherente con el sistema de funcionamiento de las universidades, que puede efectivamente tener títulos distintos en cada uno de los centros que la componen. La incoherencia, y la anomalía que supone esta exigencia, se acentúa si tenemos en cuanta el nuevo modo de diseñar los títulos y planes de estudios que existe en España desde la entrada en vigor del Real Decreto 1393/2007, de 29 de octubre. Como es bien sabido, la entrada en vigor de este Real Decreto ha supuesto el fin del sistema cerrado de títulos universitarios que existía en España, el llamado catálogo, para ser sustituido por otro sistema abierto de registro. Según este nuevo sistema de registro es muy difícil, casi imposible podríamos decir, que existan dos títulos universitarios exactamente iguales, ya que según los párrafos 4 y 5 del art.I2 de ese Real Decreto, sólo el 25\% del plan de estudios debe contener algunas de las materias básicas de la lista de muy genéricas materias que existen en el anexo $2^{\circ}$ de la misma norma, y además estas muy genéricas materias pueden concretarse en muy variadas asignaturas. Otra prueba de que en España cada título universitario, con muy pequeñas excepciones, va a ser genuino, es que el proceso de verificación o aprobación de los nuevos títulos va ligado al centro en el que se va a impartir, tal y como resulta del punto I -descripción del título-, del Anexo I del RD I393/2007.

Por ello no parece lógico, y más bien una restricción innecesaria e injustificada, que en la situación descrita se vaya a exigir precisamente ese requisito de implantación previa en la universidad expedidora del título. Lo importante es que se trate de títulos universitarios oficiales, y eso se acredita con la expedición del título, y en su caso la emisión de los certificados curriculares correspondientes, pero nada más debería ser necesario.

Analizando esta última disposición, desde un punto de vista distinto, este artículo es inútil, dado que es precisamente el hecho de que se haya expedido un título, es el que acredita que el título está implantado. Es decir, la existencia del título mismo emitido por la Universidad de que se trate, es precisamente lo que prueba que el título está implantado, por lo que esta disposición sólo puede llevar a confusión, o a una injusta aplicación restrictiva de derechos.

IV.2.3 Títulos que reconozcan más de $15 \%$ de créditos por ejercicio profesional.

No serán objeto de homologación, equivalencia a titulación y a nivel académico universitario oficial o convalidación, los siguientes títulos o estudios expedidos o realizados en el extranjero: e) Los títulos obtenidos por reconocimiento de ejercicio profesional en un porcentaje superior al 15 por ciento del total de créditos que constituyen el plan de estudios.

\footnotetext{
${ }^{9}$ http://estudos.udc.es/es/study/start/662GoIVoI
} 
Este artículo guarda evidente relación con el 6.3 del Real Decreto I393/2007, de 29 de octubre, que establece la ordenación de las enseñanzas universitarias oficiales: Artículo 6 Reconocimiento $y$ transferencia de créditos. 3. El número de créditos que sean objeto de reconocimiento a partir de experiencia profesional o laboral $y$ de enseñanzas universitarias no oficiales no podrá ser superior, en su conjunto, al 15 por ciento del total de créditos que constituyen el plan de estudios. El reconocimiento de estos créditos no incorporará calificación de los mismos por lo que no computarán a efectos de baremación del expediente.

Parece un exceso evidente de nuestra normativa, el pretender entrar en como otros sistemas universitarios establecen sus criterios en el diseño de los planes de estudio y títulos. Podríamos hablar, sin lugar a dudas, de una intromisión poco legítima, y de alguna manera una falta de respeto, poco acorde con el espíritu de los acuerdos y pactos internacionales sobre la materia. El gobierno español se debería limitar a comprobar la legitimad del título universitario del interesado, es decir que se trata de un título verdadero, de una institución universitaria o de educación superior legalmente establecida, y que el solicitante es su legítimo poseedor, así como a estudiar el contenido curricular en los casos en los que se solicite la nueva homologación profesional. Cualquier otra cosa, es decir, entrar en los concretos criterios para el diseño del plan de estudios o la obtención de créditos, supone traspasar los límites de lo razonable. De alguna manera es como si las limitaciones a la autonomía universitaria, quisieran traspasar fronteras, y llegar hasta las universidades extranjeras.

Además tampoco esta disposición ahora impugnada, parece ser muy coherente con el art. I2.6 del citado RD 1393/2007, de 29 de octubre, en cuanto este concede a las universidades la capacidad que en sus planes de estudios programen prácticas que pueden llegar a un extensión máxima de hasta el 25\% de los créditos del título universitario. ${ }^{\text {10 }}$

IV.3 Incompatibilidades restrictivas

Decía el art. 3.2 c) y d) del RD 967/20I4, de 2i de noviembre, en su versión original antes de la reforma que propició el Real Decreto I95/2016, de I3 de mayo.

2. No serán objeto de homologación, equivalencia a titulación y a nivel académico universitario oficial o convalidación, los siguientes títulos o estudios expedidos o realizados en el extranjero:

c) Los títulos que hayan sido ya homologados en España, o los estudios superados para su obtención que hayan sido ya objeto de convalidación para continuar estudios en España.

d) Los títulos que hayan sido objeto en España de un procedimiento de homologación o de equivalencia a titulación y a nivel académico universitario oficial en los que haya recaído resolución respecto a la misma solicitud.

${ }^{10} 6$. Si se programan prácticas externas, éstas tendrán una extensión máxima del 25 por ciento del total de los créditos del título, $y$ deberán ofrecerse preferentemente en la segunda mitad del plan de estudios 
Dice asimismo el artículo I8 del mismo RD 967/20I4, de 2I de noviembre: Estudios extranjeros objeto de convalidación. 2. Cuando los estudios hayan concluido con la obtención de un título extranjero que dé acceso a una profesión regulada, el interesado podrá optar entre solicitar la homologación por el título universitario oficial español correspondiente o la convalidación de estudios, teniendo en cuenta que ambas posibilidades no pueden solicitarse simultáneamente. Cuando se haya solicitado la homologación del título y ésta haya sido denegada, el interesado podrá solicitar la convalidación parcial de sus estudios, siempre que la denegación no se haya fundado en alguna de las causas recogidas en el artículo 3.2.

Los artículos que acabamos de transcribir, regulan lo que podríamos llamar el régimen de incompatibilidades entre los distintos procedimientos que establece el nuevo Real Decreto de homologaciones para dar efectividad en España a títulos universitarios extranjeros. Estas tres disposiciones regulan la cuestión de un modo bastante poco ordenado e incoherente, cayendo a veces en la contradicción o en el solapamiento. Más aún si le añadimos la Disposición Transitoria primera párrafo $2^{\circ}$ de la que hablaremos más adelante.

Por un lado el párrafo d) del artículo 3.2 establece lo que podríamos llamar la norma general de incompatibilidad entre los tres procedimientos regulados: homologación declaración de equivalencia y convalidación. Este artículo parece jugar el papel de regla principal de este régimen de incompatibilidades, estableciendo lo que podríamos llamar una prohibición total: el que haya conseguido algo ya no tiene derecho a conseguir nada más.

De la redacción de este párrafo d) del artículo 3.2 se puede llegar incluso a una conclusión -peor todavía para los potenciales intereses de los titulados universitarios extranjeros-, de que la incompatibilidad se da aunque la resolución del expediente previo no haya sido favorable. Lo que se dice en este apartado d), es que el que hayan sometido su título o un procedimiento cualquiera de estos, ya no puede solicitar iniciar el procedimiento de otro cualquiera de ellos, y lo dice sin especificar si la resolución que impide iniciar un nuevo procedimiento, ha tenido que ser positiva, o si la incompatibilidad se produce aunque la resolución previa haya sido negativa. Incompatibilidad, en la que -como acabamos de decir-, también incide el párrafo $2^{\circ}$ de la DT primera de este RD 967/20I4, que analizaremos más adelante.

La redacción de este artículo parece contradictoria con la del párrafo anterior el c), ya que ahí se indica que la incompatibilidad resulta sólo cuando ya se ha obtenido una homologación o una convalidación, es decir cuando el resultado ha sido positivo. En este párrafo c) se establece la incompatibilidad entre haber conseguido una homologación en España de un título extranjero, o haber conseguido una convalidación, y cualquiera de los otros cuatro nuevos procedimientos regulados en este nuevo Real Decreto de homologaciones, por lo que podríamos llegar a la conclusión de que en este párrafo no se prohíbe el que quien haya obtenido una previa declaración de equivalencia pueda continuar por ejemplo con un procedimiento de convalidación, por lo que en ese aspecto este párrafo se entraría en clara contradicción con el siguiente párrafo, -el d)-, que como hemos dicho, parece establecer una incompatibilidad general de todos con todos. 
Sea como sea, de este especie de galimatías de prohibiciones e incompatibilidades que establecen estos dos párrafos, se llegaba a la conclusión de que todos los caminos estaban cerrados una vez que se había intentado uno, y que no había vuelta atrás, que en este campo uno se la tiene que jugar a una sola carta. Para mayor confusión, a su vez el artículo i8 establece la posibilidad de ir a un procedimiento de convalidación después de haber intentado una homologación, sólo cuando esta haya fracasado.

Al menos la reciente reforma de esta norma por el Real Decreto I95/20I6, de I3 de mayo, parece que está haciendo que en el sistema empiece a aparecer un poco de cordura, ya que ha hecho que se elimine la incompatibilidad entre la convalidación y el resto de procedimientos, dado que el actual apartado c) del artículo 3.2 ha eliminado el vocablo convalidación de su redacción. c) Los títulos que hayan sido objeto en España de un procedimiento de homologación o de equivalencia a titulación y a nivel académico universitario oficial en los que haya recaído resolución respecto a la misma solicitud.

Con independencia de lo que a continuación tenemos que decir, lo cierto es que para dar una mínima coherencia a lo regulado en estas tres disposiciones, al menos deberíamos interpretar que la resolución a la que hace referencia el artículo 3.2 c), y la DT primera 2, debería ser siempre positiva. Interpretación que ya adelantamos, no es la que de momento está sosteniendo el MECD. En cualquier caso, el problema principal de estas tres disposiciones, que justificarían una posible nulidad, no es ya el que se establezca una incompatibilidad cuando no haya una resolución previa positiva, si no es el hecho mismo del establecimiento de un régimen de incompatibilidad entre cada una de las opciones que establece este Real Decreto. En efecto, carece totalmente de sentido, el que se establezca un régimen de incompatibilidades como el que acabamos de describir: ¿qué razón había para que un titulado universitario extranjero, o un ciudadano español que está en posesión de un título universitario extranjero, una vez obtenida la declaración de equivalencia de su título, o incluso la homologación del mismo, no pudiera someterlo a un procedimiento de convalidación en una cualquiera universidad española, para poder cursar así otras carreras distintas, y obtener nuevos títulos universitarios?. Afortunadamente esta limitación se ha levantado, pero no así, la incompatibilidad entre declaración de equivalencia y homologación, que todavía persiste.

\section{IV.4 Régimen transitorio retroactivo y limitativo.}

Dice la DT primera $2^{\circ}$ párrafo: En los supuestos de solicitudes de homologación tramitadas conforme al Real Decreto 285/2004, de 20 de febrero, por el que se regulan las condiciones de homologación y convalidación de títulos $y$ estudios extranjeros de educación superior, o al Real Decreto 86/1987, de 16 de enero, por el que se regulan las condiciones de homologación de títulos extranjeros de educación superior, en los que haya recaído resolución en el momento de entrada en vigor de esta norma, no podrá iniciarse un nuevo procedimiento de homologación o de equivalencia a titulación y a nivel académico, con base en el presente real decreto, por lo que las solicitudes de inicio de nuevos procedimientos serán inadmitidas. 
Según esta disposición transitoria, todo aquel que hubiera tramitado un procedimiento de homologación conforme a normativas anteriores, en el hubiere recaído una resolución, no tendrá derecho a realizar una nueva solicitud al amparo de lo regulado en este nuevo Real Decreto. Como se dijo en el capítulo anterior, en un mismo sentido se pronuncia el art 3.2 c) del mismo Real Decreto 967/20I4, en la versión dada por la disposición final 4 del Real Decreto I95/2016, de I3 de mayo. Insistimos en que ninguna de ambas normas aclara si la resolución previa, ha tenido que ser positiva, o esta limitación se extiende también a las resoluciones negativas. Y tampoco se dice nada sobre la firmeza de las resoluciones.

IV.4.I. La no especificación de que la resolución previa haya sido positiva.

La no inclusión de la palabra positiva junto al término resolución en este párrafo segundo de la disposición transitoria primera, puede suponer una injusta limitación de los derechos de los titulados universitarios extranjeros. De hecho, y como era de prever el MECD está interpretando de esta manera la norma, y denegando la tramitación de nuevos expedientes administrativos aunque la resolución previa haya sido negativa.

Carece de toda lógica, el que, habiendo pretendido una resolución positiva de la homologación de su título, no lo hubiere conseguido, no pueda ahora volver a intentarlo a la luz de una nueva normativa, para bien solicitar nuevamente la homologación, o bien acogerse a la posibilidad de solicitud de equivalencia que ha establecido como novedad este Real Decreto.

Hemos de partir de la base, como hemos ido explicando, de que el marco normativo y jurisprudencial ha cambiado mucho en los últimos años sobre este instituto jurídico de la homologación, y ha introducido nuevas variantes, menos exigentes o más livianas, en relación a la clásica homologación de título a título que se regulaba en el ya clásico Real Decreto 86/1987, de i6 de enero, que exigía un estudio previo de cargas y contenidos. Por ello con toda seguridad, nos podemos encontrar en la actualidad, con casos como los siguientes:

- Personas aun intentándolo, no hayan podido homologar su título universitario con arreglo al sistema del RD 86/87, por falta de equiparación entre las cargas y contenidos del título universitario extranjero estudiado, y los títulos del catálogo español vigente en este momento, y que ahora por aplicación de la citada DT primera párrafo $2^{\circ}$ del RD $967 / 20 I 4$, no pueda acceder a esta modalidad más liviana $\mathrm{o}$ «soft» de homologación.

- Personas que aun intentándolo, no hayan podido homologar su título universitario extranjero, porque la administración rechazó su solicitud de homologación, por haber estudiado en un centro español no autorizado, aunque estos estudios se hubieran realizado antes de la entrada en vigor de la LOU en enero de 2002. Y todo ello porque la administración de modo claramente erróneo, aplicó un criterio restrictivo ante un vacío legal, o retroactivo de modo y perjudicial a los intereses de los administrados. 
En ambos casos hubiera sido mucho mejor una actitud pasiva, y no haber intentado ningún tipo de movimiento administrativo. ¿Tiene sentido jurídico el que se prohíba intentar acceder a esta posibilidad más liviana de homologación, hoy llamada declaración de equivalencia, al que intento una homologación plena y no la pudo conseguir, o ni siquiera se llegó a tramitar, sea por las razones que fuera?. No creemos que se puede aplicar el instituto jurídico del hecho consentido a estos casos, porque se trata de una figura jurídica la de la declaración de equivalencia-, completamente nueva.

IV.4.2 ¿Y si la resolución previa ha sido positiva?

Pero es que en realidad, las mismas razones y fundamentos de derecho, que detallaremos en el capítulo siguiente que harían nula una DT como la analizada, cuando la resolución previa fuera negativa, también podría aplicarse a los casos en que la resolución previa haya sido positiva. ¿Qué sentido tiene el impedir al administrado poder someter su título a un nuevo proceso de homologación, sobre todo cuando este es más adecuado a su título, como por ejemplo el de los «Bachelor» Británicos, que se quedaron solo con el nivel diplomado, cuando el de grado es mucho más adecuado, máxime cuando en España ya se han aprobado los grados de 3 cursos o I80 ETCS?

IV.5. Exigencia de nivel de idioma.

Otra novedad del régimen de homologaciones actual lo encontramos en el art. Io 3 b) que establece la necesidad de acreditar competencia lingüística para poder obtener la nueva homologación que da acceso al ejercicio de profesiones reguladas. Tampoco merece una crítica favorable la introducción de esta exigencia por varios motivos:

a) Primero por su inconcreción, ya que no se especifica el nivel de exigencia, ni da ninguna otra referencia, ni lo delega en una posterior regulación ministerial.

b) Tampoco concreta los idiomas; acaso no se podría entender que un momento de pro bilingüismo inglés en España, el conocimiento de este idioma podría ser más que suficiente para el ejercicio de muchas profesiones en España.

c) Tampoco se le ve ningún sentido como requisito de la homologación de un título universitario. Puede tener sentido como requisito para el acceso a un puesto en la administración, pero no para la homologación de un título.

d) No es un requisito que podamos encontrar en el RD I837/2008 ${ }^{\mathrm{II}}$, sobre reconocimiento profesional, especialmente en los artículos IO, 2I y 22.

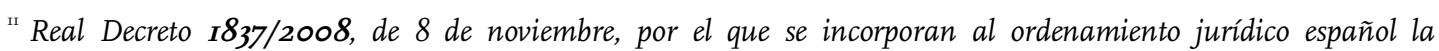
Directiva 2005/36/CE, del Parlamento Europeo y del Consejo, de 7 de septiembre de 2005, y la Directiva 2006/100/CE, del Consejo, de 20 de noviembre de 2006, relativas al reconocimiento de cualificaciones profesionales, así como a determinados aspectos del ejercicio de la profesión de abogado.
} 


\section{Normativa marco}

El objeto de este apartado es analizar un conjunto de normas, unas de carácter más genérico, y otra más específico, y casi todas ellas de rango superior, frente a las que puede chocar la normativa analizada.

\section{V.r. Principio de igualdad europea}

Parece evidente que las numerosas restricciones y limitaciones analizadas, puede suponer un tratamiento desigual a los poseedores de una titulación universitaria europea con independencia de cuál sea la nacional del titulado-, con respecto al poseedor de una titulación universitaria española. Algunas de las normas afectadas puedes ser estas:

- Convenio para la protección de los derechos humanos y de las libertades fundamentales, hecho en Roma el 4 de noviembre de I950 del Consejo de Europa. Art. I4; prohibición de discriminación. ${ }^{\text {I2 }}$

- Tratado de la unión europea de 7 de febrero de 1992 firmado en Maastricht, con las incorporaciones del Tratado de Lisboa. Arts. $2^{\text {I3 }} \mathrm{y}^{\mathrm{I}}$, derechos fundamentales

- Carta de los derechos fundamentales de la Unión Europea (2000/c 364/or), principio de igualdad y no discriminación. ${ }^{\text {I5 }}$

\footnotetext{
${ }^{12}$ Artículo 14. Prohibición de discriminación. El goce de los derechos y libertades reconocidos en el presente Convenio ha de ser asegurado sin distinción alguna, especialmente por razones de sexo, raza, color, lengua, religión, opiniones políticas u otras, origen nacional o social, pertenencia a una minoría nacional, fortuna, nacimiento o cualquier otra situación.
}

${ }^{13}$ Artículo 2. La Unión se fundamenta en los valores de respeto de la dignidad humana, libertad, democracia, igualdad, Estado de Derecho y respeto de los derechos humanos, incluidos los derechos de las personas pertenecientes a minorías. Estos valores son comunes a los Estados miembros en una sociedad caracterizada por el pluralismo, la no discriminación, la tolerancia, la justicia, la solidaridad y la igualdad entre mujeres y hombres.

${ }^{14}$ Artículo 6. I. La Unión reconoce los derechos, libertades y principios enunciados en la Carta de los Derechos Fundamentales de la Unión Europea de 7 de diciembre de 2000, tal como fue adaptada el i2 de diciembre de 2007 en Estrasburgo, la cual tendrá el mismo valor jurídico que los Tratados.

Las disposiciones de la Carta no ampliarán en modo alguno las competencias de la Unión tal como se definen en los Tratados.

Los derechos, libertades y principios enunciados en la Carta se interpretarán con arreglo a las disposiciones generales del título VII de la Carta por las que se rige su interpretación y aplicación y teniendo debidamente en cuenta las explicaciones a que se hace referencia en la Carta, que indican las fuentes de dichas disposiciones.

2. La Unión se adherirá al Convenio Europeo para la Protección de los Derechos Humanos y de las Libertades Fundamentales. Esta adhesión no modificará las competencias de la Unión que se definen en los Tratados.

3. Los derechos fundamentales que garantiza el Convenio Europeo para la Protección de los Derechos Humanos y de las Libertades Fundamentales y los que son fruto de las tradiciones constitucionales comunes a los Estados miembros formarán parte del Derecho de la Unión como principios generales.

${ }^{15}$ Artículo 20 Igualdad ante la ley. Todas las personas son iguales ante la ley

Artículo 2I. No discriminación.

I. Se prohíbe toda discriminación, y en particular la ejercida por razón de sexo, raza, color, orígenes étnicos o sociales, características genéticas, lengua, religión o convicciones, opiniones políticas o de cualquier otro tipo, pertenencia a una minoría nacional, patrimonio, nacimiento, discapacidad, edad u orientación sexual. 


\section{V.2. Convenios europeos sobre reconocimiento de cualificaciones}

- Convenio sobre reconocimiento de cualificaciones relativas a la educación superior en la región europea (número ${ }_{1} 65$ del Consejo de Europa), hecho en Lisboa el II de abril de I997. (Ratificado por España el 20 de febrero de 2009. Publicado el instrumento de ratificación del convenio en el BOE $\mathrm{n}^{\circ}$ 29I de 3 de diciembre de 2009). ${ }^{16}$

- Directiva 2013/55/UE del Parlamento Europeo y del Consejo, de 20 de noviembre de 20I3, por la que se modifica la Directiva 2005/36/CE relativa al reconocimiento de cualificaciones profesionales y el Reglamento (UE) $\mathrm{n}^{\circ}$ IO24/2012 relativo a la cooperación administrativa a través del Sistema de Información del Mercado Interior («Reglamento IMI»). ${ }^{\text {I }}$

V.3 Principio pro movilidad universitaria, pro colaboración y pro construcción de un sistema universitario único.

De las normas y convenios que citaremos a continuación, se deriva la necesidad de que los países colaboren entre sí en la construcción de un espacio común educativo, fomentando la cooperación entre ellos, y la movilidad de profesores y estudiantes entre los países firmantes. En concreto el texto refundido del tratado de la Unión Europea, se habla específicamente de la movilidad y del desarrollo de la dimensión europea de la enseñanza, todo ello obviamente relacionado con principios generales y constitutivos de la Unión

2. Se prohíbe toda discriminación por razón de nacionalidad en el ámbito de aplicación del Tratado constitutivo de la Comunidad Europea y del Tratado de la Unión Europea y sin perjuicio de las disposiciones particulares de dichos Tratados.

${ }^{16}$ Sección III. Principios fundamentales relativos a la evaluación de las cualificaciones.

Artículo III.I

I. Los titulares de cualificaciones conferidas en una Parte podrán obtener, previa solicitud al órgano competente, una evaluación de dichas cualificaciones.

2. Nadie será objeto, a este respecto, de ninguna discriminación basada en el sexo, la raza, el color, la discapacidad, la lengua, la religión, las opiniones políticas o de cualquier otro tipo, el origen nacional, étnico o social, la pertenencia a una minoría nacional, los bienes personales, el nacimiento o cualquier otra situación, ni tampoco en ninguna otra circunstancia ajena al valor de la cualificación cuyo reconocimiento se solicita. A fin de garantizar este derecho, cada Parte se compromete a adoptar las disposiciones necesarias para la evaluación de una solicitud de reconocimiento, teniendo en cuenta exclusivamente los conocimientos y las aptitudes adquiridos.

${ }^{17}$ 49) El artículo 59. Transparencia.

3. Los Estados miembros examinarán si, en su ordenamiento jurídico, los requisitos que limitan el acceso a una profesión o su ejercicio a los titulares de un título de formación específica, en particular la utilización de títulos profesionales y las actividades profesionales autorizadas sobre la base de dicho título, denominados en el presente artículo «requisitos», son compatibles con los principios siguientes:

a) los requisitos no podrán ser ni directa ni indirectamente discriminatorios por razón de nacionalidad o de lugar de residencia;

b) los requisitos deberán estar justificados por una razón imperiosa de interés general;

c) los requisitos deberán ser los adecuados para garantizar la consecución de los objetivos perseguidos y no exceder de lo necesario para alcanzar el objetivo. 
Europea, como son la construcción de un mercado interior, o lo que es lo mismo, un espacio sin fronteras interiores, propicio para la libre circulación de mercancías, personas, servicios y capitales.

Aunque el llamado proceso de Bolonia, de construcción del espacio europeo de educación superior, no tenga exactamente las características de un tratado internacional, sino más bien de un acuerdo intergubernamental, no es menos cierto que sus principios, fines, y propósito, nos ayudan a contextualizar el fondo en el que deben regularse el sistema universitario español. De la declaración conjunta de Ministros de Educación de BOLONIA de I9 de junio de I999, se extrae los principios que configuran este proceso de convergencia europeo en el ámbito universitario. ${ }^{18}$ Los objetivos del proceso de Bolonia, y de llevar a España al Espacio Europeo de Educación Superior, se reflejan en muchas normas nacionales empezando por el art. $88^{19}$ de la Ley Orgánica de Universidades. La estructura

\footnotetext{
${ }^{18}$ A la vez que afirmamos nuestra adhesión a los principios generales que subyacen en la declaración de la Sorbona, nos comprometemos a coordinar nuestras políticas para alcanzar en un breve plazo de tiempo, y en cualquier caso dentro de la primera década del tercer milenio, los objetivos siguientes, que consideramos de capital importancia para establecer el área Europea de educación superior y promocionar el sistema Europeo de enseñanza superior en todo el mundo: La adopción de un sistema de titulaciones fácilmente comprensible y comparable, incluso a través de la puesta en marcha del Suplemento del Diploma, para promocionar la obtención de empleo y la competitividad del sistema de educación superior Europeo. Adopción de un sistema basado esencialmente en dos ciclos fundamentales, diplomatura (pregrado) y licenciatura (grado). El acceso al segundo ciclo requerirá que los estudios de primer ciclo se hayan completado, con éxito, en un periodo mínimo de tres años. El diploma obtenido después del primer ciclo será también considerado en el mercado laboral Europeo como nivel adecuado de cualificación. El segundo ciclo conducirá al grado de maestría y/o doctorado, al igual que en muchos países Europeos.
}

El establecimiento de un sistema de créditos - similar al sistema de ETCS- como medio adecuado para promocionar una más amplia movilidad estudiantil. Los créditos se podrán conseguir también fuera de las instituciones de educación superior, incluyendo la experiencia adquirida durante la vida, siempre que esté reconocida por las Universidades receptoras involucradas.

Promoción de la movilidad, eliminando los obstáculos para el ejercicio efectivo de libre intercambio, prestando una atención particular a:

- el acceso a oportunidades de estudio y formación y servicios relacionados, para los alumnos.

- el reconocimiento y valoración de los periodos de estancia en instituciones de investigación, enseñanza y formación Europeas, sin perjuicio de sus derechos

estatutarios, para los profesores, investigadores y personal de administración.

- Promoción de la cooperación Europea en aseguramiento de la calidad con el objeto de desarrollar criterios y metodologías comparables.

- Promoción de las dimensiones Europeas necesarias en educación superior, particularmente dirigidas hacia el desarrollo curricular, cooperación entre instituciones, esquemas de movilidad y programas de estudio, integración de la formación e investigación.

${ }^{19}$ I. A fin de promover la más amplia movilidad de estudiantes y titulados españoles en el espacio europeo de enseñanza superior, el Gobierno, previo informe del Consejo de Universidades, adoptará las medidas que aseguren que los títulos oficiales expedidos por las universidades españolas se acompañen del suplemento europeo al título.

2. Asimismo, el Gobierno, previo informe del Consejo de Universidades, establecerá las normas necesarias para que la unidad de medida del haber académico, correspondiente a la superación de cada una de las materias que integran los planes de estudio de las diversas enseñanzas conducentes a la obtención de títulos de carácter oficial y validez en todo el territorio nacional, sea el crédito europeo.

3. El Gobierno, las Comunidades Autónomas y las universidades fomentarán la movilidad de los estudiantes en el espacio europeo de enseñanza superior a través de programas de becas y ayudas y créditos al estudio o, en su caso, complementando los programas de becas y ayudas de la Unión Europea. 
misma de tres ciclos del sistema universitario de educación superior que se refleja tanto en la LOU, y se desarrolla en el Real Decreto 1393/2007, es otro evidente reflejo del proceso de Bolonia. Otros ejemplos claros del reflejo del proceso de Bolonia en la normativa española son los siguientes:

- Real Decreto I044/2003, de I de agosto, por el que se establece el procedimiento para la expedición por las universidades del Suplemento Europeo al Título.

- Real Decreto II25/2003, de 5 de septiembre, por el que se establece el sistema europeo de créditos y el sistema de calificaciones en las titulaciones universitarias de carácter oficial y validez en todo el territorio nacional.

Pues bien, en un contexto de cooperación, de colaboración, de facilitación del acceso y la movilidad, de construcción de un espacio de educación superior común, poco casan muchas de las normas que están siendo objeto de análisis. No casan, más bien chocan frontalmente las normas que establecen un absurdo y limitativo régimen de incompatibilidades, tampoco las normas que de alguna manera hacen aflorar una desconfianza del sistema universitario español hacia otros sistemas universitarios. Y menos cabe aún, cuando esa desconfianza se vierte sobre sistemas universitarios del Espacio Europeo de Educación Superior.

Como puede ser compatible con los principios que acabamos de describir normas como las comentadas que:

- No permiten homologar títulos universitarios extranjeros cuando ese título se ha obtenido después de reconocer a la experiencia profesional más I5\% del contenido. Art. 3.2. e).

- Se intenta aplicar a las universidades extranjeras, las mismas normas que se establecen en España para el acceso a la universidad. Art. 7 b.

- Se establece la necesidad de una acreditación adicional acerca las competencias formativas adquiridas, como si no bastara con el hecho mismo de la expedición del título o de los certificados curriculares. En definitiva como si -en términos generales hablando-, el estado español no se fiara de lo que hacen las universidades extranjeras. Art. 7 d)

Versiones consolidadas del Tratado de la Unión Europea y del Tratado de Funcionamiento de la UNIÓN EUROPEA. 20I2/C 326/OI.

- Mercado interior. $^{20}$

\footnotetext{
${ }^{20}$ Artículo 26 (antiguo artículo I4 TCE)

I. La Unión adoptará las medidas destinadas a establecer el mercado interior o a garantizar su funcionamiento, de conformidad con las disposiciones pertinentes de los Tratados.

2. El mercado interior implicará un espacio sin fronteras interiores, en el que la libre circulación de mercancías, personas, servicios y capitales estará garantizada de acuerdo con las disposiciones de los Tratados.
} 
- Educación, formación profesional, juventud y deporte. ${ }^{21}$

V.4. Los principios que han de regir la actuación normativa de la administración.

V.4.I Principio de la irretroactividad de las disposiciones sancionadoras no favorables o restrictivas de derechos individuales, y de la retroactividad de las favorables.

Este principio de nuestro ordenamiento jurídico se reflejaba históricamente en el art. 2 de nuestro código civil. ${ }^{22}$ La Constitución Española de I978, elevó en su artículo 9.3 $3^{23}$ a rango constitucional este principio, aclarando que la retroactividad podía ser posible cuando fuera positiva para los derechos individuales del ciudadano. Este mismo principio se reflejó en el art. 57 de la recientemente derogada Ley 30/1992, de 26 de noviembre, de Régimen Jurídico de las Administraciones Públicas y del Procedimiento Administrativo Común, y ha quedado plasmado en el art. $39^{24}$ de la nueva Ley 39/2015, de I de octubre, del Procedimiento Administrativo Común de las Administraciones Públicas.

3. El Consejo, a propuesta de la Comisión, definirá las orientaciones y condiciones necesarias para asegurar un progreso equilibrado en el conjunto de los sectores considerados.

${ }^{21}$ Artículo I65 (antiguo artículo I49 TCE)

I. La Unión contribuirá al desarrollo de una educación de calidad fomentando la cooperación entre los Estados miembros y, si fuere necesario, apoyando y completando la acción de éstos en el pleno respeto de sus responsabilidades en cuanto a los contenidos de la enseñanza y a la organización del sistema educativo, así como de su diversidad cultural y lingüística.

La Unión contribuirá a fomentar los aspectos europeos del deporte, teniendo en cuenta sus características específicas, sus estructuras basadas en el voluntariado y su función social y educativa.

2. La acción de la Unión se encaminará a:

- desarrollar la dimensión europea en la enseñanza, especialmente a través del aprendizaje y de la difusión de las lenguas de los Estados miembros,

- favorecer la movilidad de estudiantes y profesores, fomentando en particular el reconocimiento académico de los títulos y de los períodos de estudios

${ }^{22}$ I. Las Leyes entrarán en vigor a los veinte días de su completa publicación en el Boletín Oficial del Estado, si en ellas no se dispone otra cosa.

2. Las Leyes sólo se derogan por otras posteriores. La derogación tendrá el alcance que expresamente se disponga y se extenderá siempre a todo aquello que en la Ley nueva, sobre la misma materia, sea incompatible con la anterior. Por la simple derogación de una Ley no recobran vigencia las que ésta hubiere derogado.

3. Las Leyes no tendrán efecto retroactivo si no dispusieren lo contrario.

${ }^{23}$ 3. La Constitución garantiza el principio de legalidad, la jerarquía normativa, la publicidad de las normas, la irretroactividad de las disposiciones sancionadoras no favorables o restrictivas de derechos individuales, la seguridad jurídica, la responsabilidad y la interdicción de la arbitrariedad de los poderes públicos

${ }^{24}$ Artículo 39. Efectos.

I. Los actos de las Administraciones Públicas sujetos al Derecho Administrativo se presumirán válidos y producirán efectos desde la fecha en que se dicten, salvo que en ellos se disponga otra cosa.

2. La eficacia quedará demorada cuando así lo exija el contenido del acto o esté supeditada a su notificación, publicación o aprobación superior.

3. Excepcionalmente, podrá otorgarse eficacia retroactiva a los actos cuando se dicten en sustitución de actos anulados, así como cuando produzcan efectos favorables al interesado, siempre que los supuestos de hecho necesarios existieran ya en la fecha a que se retrotraiga la eficacia del acto y ésta no lesione derechos o intereses legítimos de otras personas. 
La imposibilidad de aplicación retroactiva de los reglamentos perjudiciales para los intereses individuales al igual con lo que sucede con los actos administrativos, es un derecho consolidado en nuestros sistema, que entre otras, ha sido reflejado de modo muy claro en la sentencia de la sala de lo contencioso administrativo del Tribunal Supremo de 7 de junio de 2.002, (rec.3II2/I995), en particular en los fundamentos de derecho IV y V. ${ }^{25}$

La otra cara del principio de la retroactividad de las disposiciones administrativas no favorables o restrictivas lo constituye precisamente el de la retroactividad de la favorables, que se deduce de modo implícito del propio art. 9.3 de la constitución, y de modo expreso del art. 39.3 de la nueva Ley 39/20I5 de Procedimiento Administrativo Común, estableciendo como límite la no lesión de derechos o intereses legítimos de terceras personas. La reciente sentencia num. 45/2016 de 26 abril de la sala de lo militar del

\footnotetext{
${ }^{25}$ CUARTO.- La jurisprudencia tiene declarado que la regla general de la irretroactividad de las leyes que, salvo expresa disposición en contrario, proclama el artículo 2.3 del Código Civil es trasplantable todavía con rigor más absoluto a las normas reglamentarias, hasta el punto de que en ciertos sectores se ha cuestionado seriamente la mera posibilidad de aplicación de dicha retroactividad, atendiendo tanto a que la potestad reglamentaria de la Administración ha de ejercerse con proyección a un futuro previsible, como a la aplicación del principio inclussio unius, exclussio alterius (si se incluye una cosa se excluye lo demás) que se desprende del mismo artículo 2.3 citado (sentencias de esta Sala de 2I de julio de I989, 8 de noviembre de I99I y I6 de septiembre de i998, recurso de apelación núm. I2366/ı99I, entre otras).

Este principio deriva de la regla general contenida en el artículo 9.3 de la Constitución y de lo preceptuado en el artículo 57.3 de la Ley 30/I992, de 26 de noviembre, de Régimen jurídico de las Administraciones Públicas y del procedimiento administrativo común. Este artículo se refiere a los actos administrativos, y no al ejercicio de la potestad reglamentaria; sin embargo, la doctrina más autorizada y la jurisprudencia se muestran conformes con la identidad de la motivación que justifica, en uno u otro caso, la limitación de retroactividad en dichos preceptos, con la que se pretende evitar enojosas intromisiones en la actividad de los administrados (sentencia de 2I de julio de I989, ya citada).
}

Esa general irretroactividad de la eficacia de los reglamentos $u$ ordenanzas no es absoluta y admite determinadas excepciones, tanto cuando se limitan a favorecer el ejercicio de derechos o intereses legítimos sin perjuicio para tercero [aplicación del principio de retroactividad in bonam partem (en lo que resulta beneficioso)], como a regular materias de procedimiento $u$ organización que resulten inocuas para los ciudadanos, e incluso cuando vengan a sustituir a otras normas reglamentarias, previamente anuladas, siempre que se respeten los límites prescritos por el artículo 57 de la Ley 30/1992.

QUINTO.- En consonancia con esta doctrina, la alegación de la parte recurrente debe ser estimada. La sentencia impugnada afirma que en caso de que se hubieran omitido los requisitos establecidos en el Reglamento de 1956 procedería la convalidación del Proyecto con arreglo al nuevo Reglamento de Bienes, atendiendo a razones de equidad y de economía procedimental.

Esta interpretación no puede ser aceptada. Se infringe con ella el principio de irretroactividad de los reglamentos a que acaba de hacerse referencia. La llamada «convalidación» del Proyecto en aplicación de una norma reglamentaria posterior supone reconocerle virtualidad para producir una mutación demanial automática aun en el caso de que no cumpla los requisitos para ello con arreglo a la norma vigente en el momento de su aprobación. Con ello se incurre en una aplicación retroactiva del nuevo Reglamento.

De acuerdo con la disposición adicional primera del Código civil, que constituye el paradigma del principio de irretroactividad de las normas, «Se regirán por la legislación anterior al Código los derechos nacidos, según ella, de hechos realizados bajo su régimen, aunque el Código los regule de otro modo o no los reconozca. Pero si el derecho apareciere declarado por primera vez en el Código, tendrá efecto desde luego, aunque el hecho que lo origine se verificara bajo la legislación anterior, siempre que no perjudique a otro derecho adquirido, de igual origen».

En el caso examinado la interpretación efectuada por la Sala conduce a atribuir a un hecho anterior al Reglamento derogado (la aprobación del Proyecto de Obras) los efectos jurídicos de demanialización que reconoce el nuevo Reglamento, en perjuicio del interés público vinculado a la existencia del camino público y del derecho de los ciudadanos a su uso 
Tribunal Supremo, estimó parcialmente un recurso contencioso disciplinario militar al entender aplicable de modo retroactivo la ley disciplinaria más favorable.

La DT primera párrafo $2^{\circ}$ del RD 967/20I4, que se ha analizado con anterioridad, al menos en lo que se refiere a la resolución precedente negativa, tiene el efecto de impedir que los ciudadanos o administrados puedan acogerse a una nueva figura jurídica, como es la declaración de equivalencia. Aunque consideráramos que dicha DT no es retroactiva en sí misma, qué duda cabe que sí que estaría impidiendo la retroactividad positiva de esta nueva categoría jurídica de la homologación, ya que, como venimos diciendo, impide que personas que en su momento no pudieron acogerse a la homologación tradicional o completa, ahora lo puedan hacer a esta nueva figura jurídica, la declaración de equivalencia.

\section{V.4.2. Principios de buena regulación administrativa}

El artículo $129^{26}$ de la nueva ley de procedimiento administrativo común, la 39/2015, ha traído a nuestro ordenamiento jurídico los principios de la buena regulación: necesidad, eficacia, proporcionalidad, seguridad jurídica, transparencia, y eficiencia. Como el propio párrafo $3^{\circ}$ del art. I29 especifica, el principio de proporcionalidad exige a la norma el que sea lo menos restrictiva posible. En realidad este principio ya estaba contemplado en el propio artículo $9.2^{27}$ del texto constitucional, al exigir a los poderes públicos que promuevan las mejores condiciones posibles para la libertad del individuo.

Lo que se desprende de ambas normas, es algo que no puede ser de más sentido común, y que entronca con la finalidad misma del derecho, y del propio estado, al menos del democrático, y es que el sentido y función de la norma jurídica no puede ser el cerrar posibilidades a los ciudadanos, o limitar sus derechos, sino más bien el contrario. El sentido de la norma tendría que ser el de crear posibilidades, establecer vías y vías de desarrollo y crecimiento, y no el contrario. Por ello la Constitución Española nos dice en el artículo 3

\footnotetext{
${ }^{26}$ I. En el ejercicio de la iniciativa legislativa y la potestad reglamentaria, las Administraciones Públicas actuarán de acuerdo con los principios de necesidad, eficacia, proporcionalidad, seguridad jurídica, transparencia, y eficiencia. En la exposición de motivos o en el preámbulo, según se trate, respectivamente, de anteproyectos de ley o de proyectos de reglamento, quedará suficientemente justificada su adecuación a dichos principios.

2. En virtud de los principios de necesidad y eficacia, la iniciativa normativa debe estar justificada por una razón de interés general, basarse en una identificación clara de los fines perseguidos y ser el instrumento más adecuado para garantizar su consecución.

3. En virtud del principio de proporcionalidad, la iniciativa que se proponga deberá contener la regulación imprescindible para atender la necesidad a cubrir con la norma, tras constatar que no existen otras medidas menos restrictivas de derechos, o que impongan menos obligaciones a los destinatarios.

4. A fin de garantizar el principio de seguridad jurídica, la iniciativa normativa se ejercerá de manera coherente con el resto del ordenamiento jurídico, nacional y de la Unión Europea, para generar un marco normativo estable, predecible, integrado, claro y de certidumbre, que facilite su conocimiento y comprensión y, en consecuencia, la actuación y toma de decisiones de las personas y empresas.

${ }^{27}$ 2. Corresponde a los poderes públicos promover las condiciones para que la libertad y la igualdad del individuo y de los grupos en que se integra sean reales y efectivas; remover los obstáculos que impidan o dificulten su plenitud y facilitar la participación de todos los ciudadanos en la vida política, económica, cultural y social.
} 
que la misión de los poderes públicos es promover las condiciones para que la libertad sea posible, y por eso el art. I29 p3 de la Ley 39/20I5, exige que las disposiciones administrativas sean lo menos restrictivas posibles. Y resulta del todo incuestionable, que estos principios, no casan de ninguna manera, con muchas de las disposiciones del RD 967/20I4, que hemos analizado, en particular el párrafo $2^{\circ}$ de la DT primera, que en el fondo tiene como finalidad única y exclusiva, la de limitar derechos de determinados administrados, a los que sin mayor motivo, se les impide el acceso a una institución jurídica de reciente creación como es la declaración de equivalencia, máxime cuando del reconocimiento de esta posibilidad, ningún mal se puede desprender a los derechos o intereses legítimos de terceros, ni menos aún, se va a realizar un aprovechamiento indebido o ilegítimo, de bienes o derechos públicos. 